\title{
Feed Point Optimization using Neural Network
}

\author{
Ruchi Varma ${ }^{1}$, Dr. Jayanta Ghosh ${ }^{2}$ \\ ${ }^{1}$ (Research Scholar, ECE, National Institute of technology, Patna, India) \\ 2 (Assistant professor, ECE, National Institute of technology, Patna, India)
}

\begin{abstract}
Microstrip antenna is gathering a lot of interest in communication systems. In this paper neural network approach has been used for calculation of feed position of microstrip antenna for maximum power transfer. This paper demonstrates the validity of neural network for the estimation of feed point of patch antenna varying with input impedance. Accuracy of the results encourages the use of Neural network. Further simulations are done using CST software.
\end{abstract}

Keywords: Microstrip antenna, Neural Network, Feed position, CST.

\section{Introduction}

The popularity of wireless communication systems has increased significantly in the last decade as evident from the applications such as mobile phones and wireless networks. As the demand for these systems increases, there is a need for advanced antennas and antenna systems with new capabilities and better performance. Recent developments in communication systems such as the global positioning systems (GPS), Wireless local network (WLAN), vehicular satellite communication and wireless communications often require antennas with compact size, low cost, light weight, low profile, conformability to planar and non-planar surfaces and ease of fabrication which cannot be met by the conventional microwave antennas.[1] Microstrip antennas are the best suited for these applications because of its coplanar configuration.

Impedance matching is a very important for designing an antenna as it decides the coupling effect. The feed point must be located at that point on the patch, where the input impedance is $50 \mathrm{ohm}$ for the resonant frequency. An error in feed point location of .01L would yield a deviation in resonant resistance of the order of $10 \mathrm{ohm}$. Perfect impedance matching leads to maximum coupling. [5]To locate the point where the impedance is $50 \mathrm{ohm}$ is difficult task and is usually done by hit and trial method. Many methods have been developed to achieve such high design accuracy. But these involve high cost experimental infrastructure and experimental time. In this paper ANNs have been used to evaluate the accurate feed point location for impedance matching.

\section{Neural Network}

Artificial neural network have been very intensively explored from eighties, they have been used for adaptive controllers. Dealing with microwaves, artificial neural network appeared here at the beginning of nineties and they have been used for modelling active and passive components, design and optimization of microwave circuits, modelling microstrip antennas, reverse modelling of microwave devices, automatic impedance matching, etc. Using artificial neural networks, microwave engineers have tried to simply a rather difficult and time consuming design of microwave systems. Artificial neural networks are electronic system of hardware or software nature, which are built according to the example of a human brain. Therefore, artificial neural network consist of many simple non- linear functional blocks of a few types, which are called neurons. Neurons are organized into layers, which are connected by highly parallel synaptic weights, artificial neural network exhibit a learning ability, which means that synaptic weights can be strengthened or reduced so that artificial neural network can react on a given input pattern by a desired output one.[6] This artificial neural network, exhibit a very high operational speed. Thus in this paper neural network approach has been used for calculation of feed position of microstrip antenna for maximum power transfer.[4]

\section{Microstrip Antenna}

In its most fundamental form, a microstrip patch antenna consists of a radiating patch on one side of a dielectric substrate which has a ground plane on the other side as shown in Fig. 1. The patch is generally made of conducting material such as copper or gold and can take any possible shape. The radiating patch and the feed lines are usually photo etched on the dielectric substrate. Rectangular and square patches are the most commonly used type of micro strip antennas. They can be used in numerous types of applications including circular polarization, beam scanning, radiation pattern control and multiple frequency operation. The basic antenna element is a thin conductor of dimensions $\mathrm{L} \times \mathrm{W}$ on a dielectric substrate of permittivity $\varepsilon_{\mathrm{r}}$ and thickness $\mathrm{h}$ backed by a conducting ground plane .[2], [3]. 


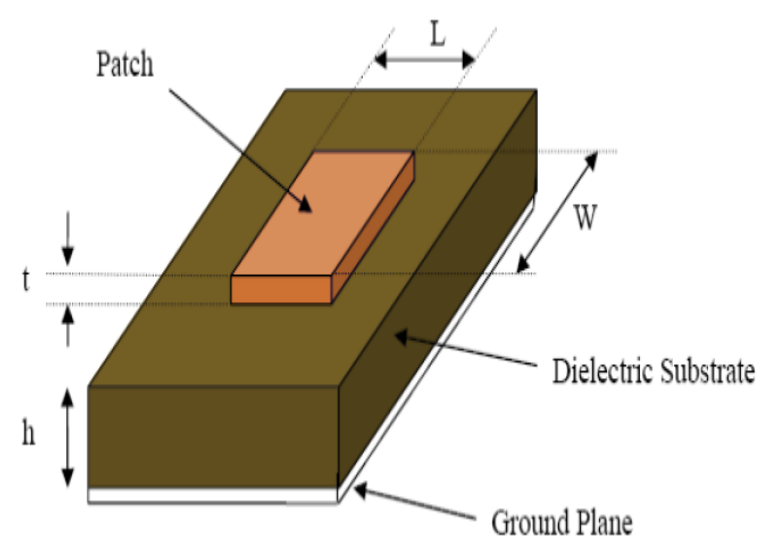

Fig 1: Microstrip antenna

\section{Feed Point Optimization}

In this paper, a microstrip antenna has been designed for Bluetooth communication purpose i.e. at a frequency (fr) of $1.575 \mathrm{GHz}$ with dielectric constant $\left(\varepsilon_{\mathrm{r}}\right) 4.36$ and substrate thickness (h) $1.6 \mathrm{~mm}$. At this frequency using the below formulae, length (L) and width (W) of the antenna has been found to be $45.307 \mathrm{~mm}$ and $58.13 \mathrm{~mm}$ respectively.

Calculation of the Width (W):

$\mathrm{W}=\frac{C 0}{(2 \times \mathrm{fr})} \sqrt{\frac{2}{\left(\varepsilon_{\mathrm{r}}+1\right)}}$

Calculation of Effective dielectric constant $\left(\varepsilon_{\text {reff }}\right)$ :

$\varepsilon_{\text {reff }}=\left(\varepsilon_{\mathrm{r}}+1\right) / 2+\frac{\left(\varepsilon_{\mathrm{r}}-1\right) / 2}{\sqrt{\left(1+12 \times \frac{\mathrm{h}}{\mathrm{w}}\right)}}$

Calculation of the length extension $(\Delta \mathrm{L})$ :

$\Delta \mathrm{L}=.412 \frac{\left(\left(\varepsilon_{\text {reff }}+.3\right) *((\mathrm{~W} / \mathrm{h})+.264)\right)}{\left(\left(\varepsilon_{\text {reff }}-.258\right) *((\mathrm{~W} / \mathrm{h})+.8)\right)}$

Calculation of effective length of patch (L):

Leff $=\mathrm{L}+2 \Delta \mathrm{L}$

$\mathrm{L}_{\text {eff }}=\frac{c}{\left(2 . \mathrm{fr} \cdot \sqrt{\left.\left(\varepsilon_{\text {reff }}\right)\right)}\right.}$

We know that the impedance of a microstrip antenna varies as shown in figure 2.

$\operatorname{Rin}\left(y=y_{0}\right)=\operatorname{Rin}(y=0) \times \cos ^{2}\left((\pi / L) \cdot y_{0}\right)$

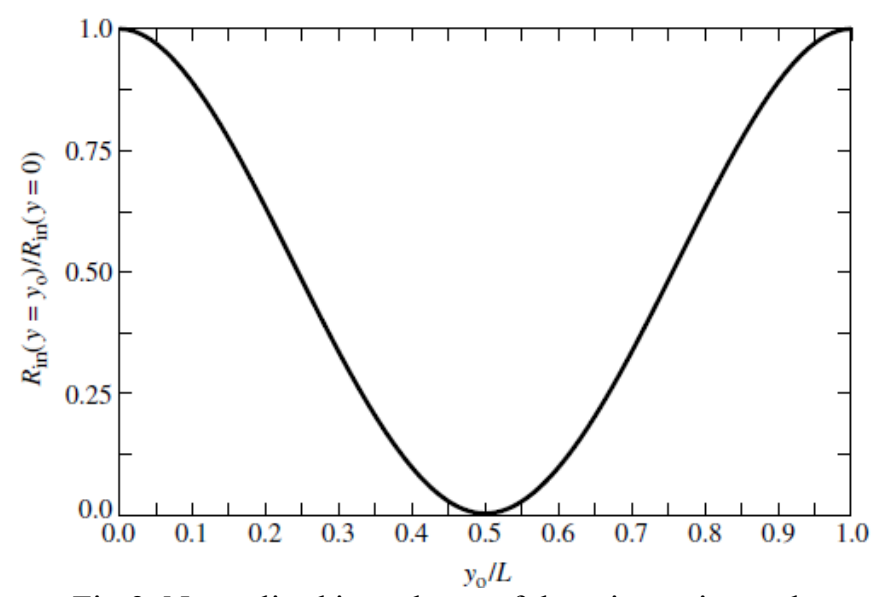

Fig:2 Normalised impedance of the microstrip patch

And the result for the normalized input impedance thus obtained is used as the training data. About 70 numbers of patterns are taken for training the network.

A feed forward multilayer architecture is used. And the Back Propagation Algorithm is used to train the feed forward neural network. Coding for training and testing algorithms of the ANN model is created in 
MATLAB software. A three layer 1-5-1 network is used for the problem. It means that there are 1 neuron in the input layer, 5 neurons in hidden layer and 1 neuron in the output layer.

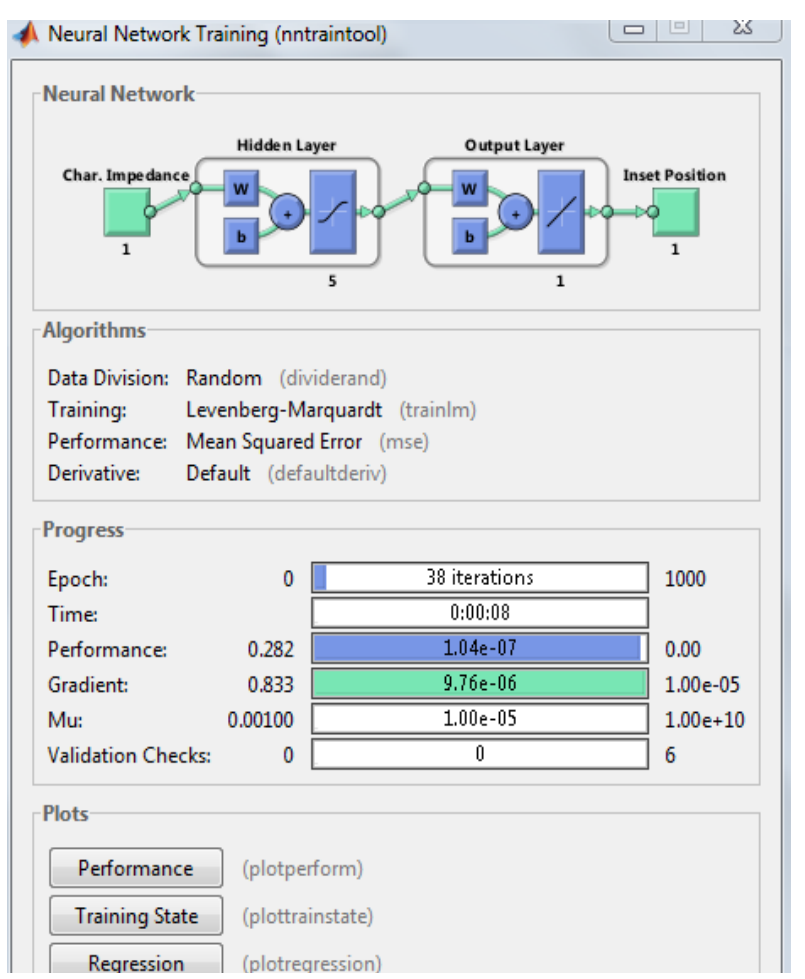

Fig. 3: NNtraintool

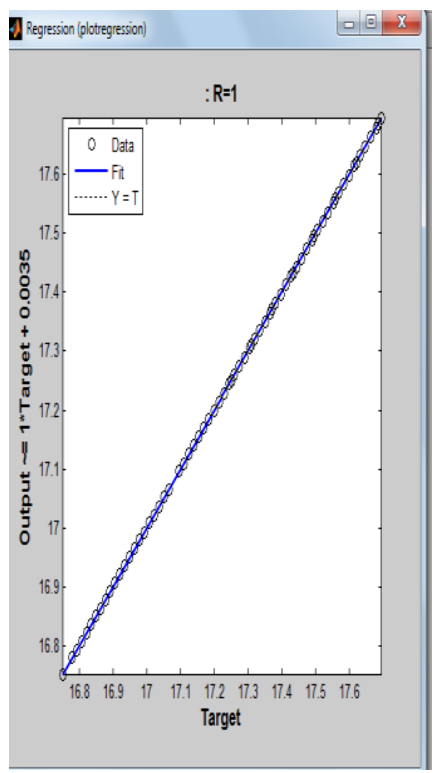

Fig 4: Regression curve

The theoretical values obtained by the transmission line model are used to compare the results. 10 patterns have been tested to see the accuracy of the neuron model.

Table 1: Comparison of ANN and Transmission Line Model Results

\begin{tabular}{|l|l|l|}
\hline Serial No. & ANN Results & Transmission Line Results \\
\hline 1 & 17.19 & 17.19 \\
\hline 2 & 17.131 & 17.1304 \\
\hline 3 & 17.072 & 17.072 \\
\hline 4 & 17.014 & 17.0143 \\
\hline 5 & 16.956 & 16.9558 \\
\hline 6 & 16.898 & 16.898 \\
\hline 7 & 16.841 & 16.8424 \\
\hline 8 & 16.785 & 16.784 \\
\hline 9 & 16.729 & 16.7331 \\
\hline 10 & 17.081 & 17.0806 \\
\hline
\end{tabular}

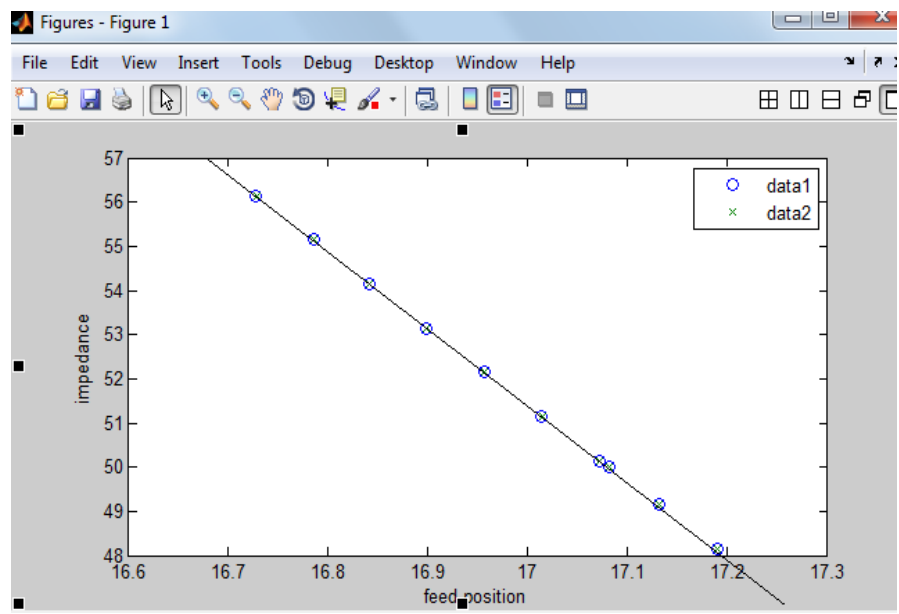

Fig. 5: Comparison between ANNs \& theoretical values 
Fig.5. reflects the comparison made among the results obtained from ANNs (data1) and theoretical values obtained by transmission line formulae( data2). Performance of the neural network based estimators was found to be excellent.

\section{Results and Discussions}

Thus feed point is found to be $17.08 \mathrm{~mm}$ for $50 \mathrm{ohm}$ impedance. An inset feed antenna is simulated using CST software. A frequency range of $1-2 \mathrm{GHz}$ is selected and 100 frequency points are selected over this range to obtain accurate results. The centre frequency is selected as the one at which the $S_{11}$ is minimum. The bandwidth can be calculated from the $S_{11}$ plot. The bandwidth of the antenna can be said to be those range of frequencies over which the $\mathrm{S}_{11}$ is greater than $-10 \mathrm{~dB}(-10 \mathrm{~dB}$ corresponds to a VSWR of 2 which is an acceptable figure).

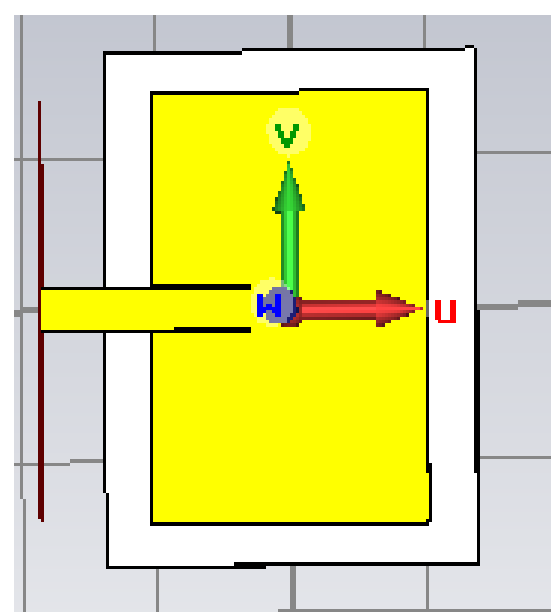

Fig.6 : Patch Antenna at $1.575 \mathrm{GHz}$

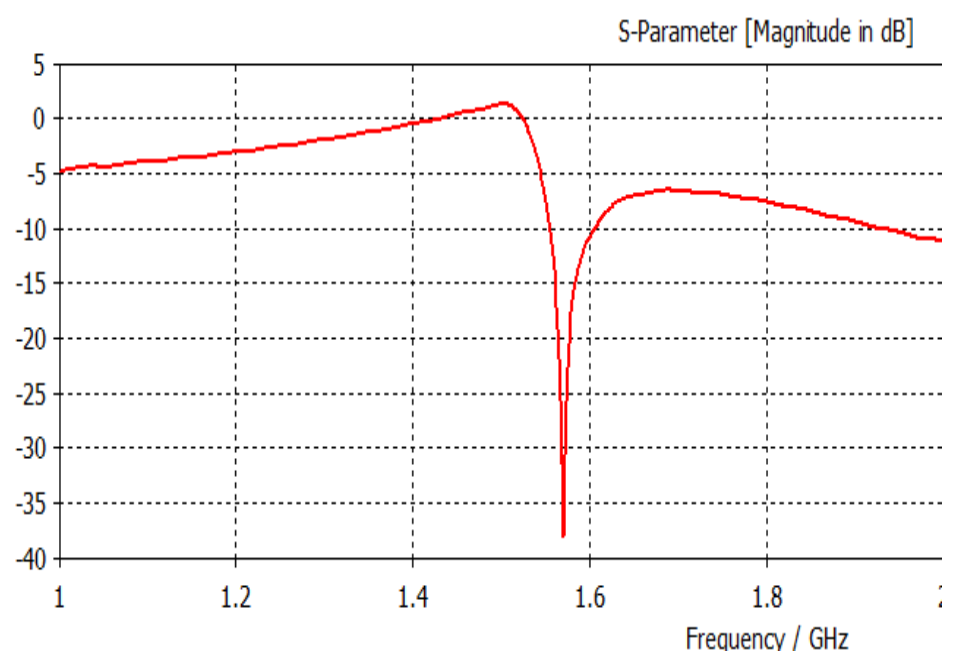

Fig.7: $\mathrm{S}_{11}$ Plot at $1.575 \mathrm{GHz}$

Table 2: Summary of the obtained results

\begin{tabular}{|l|l|l|l|l|l|l|l|}
\hline $\begin{array}{l}\text { Resonant } \\
\text { frequency } \\
(\mathrm{GHz})\end{array}$ & $\begin{array}{l}\text { Substrate } \\
\text { thickness } \\
(\mathrm{mm})\end{array}$ & $\begin{array}{l}\text { Optimum } \\
\text { patch length } \\
(\mathrm{mm})\end{array}$ & $\begin{array}{l}\text { Optimum } \\
\text { patch width } \\
(\mathrm{mm})\end{array}$ & $\begin{array}{l}\text { Feed } \\
\text { position } \\
(\mathrm{mm})\end{array}$ & $\begin{array}{l}\mathrm{S}_{11} \\
(\mathrm{~dB})\end{array}$ & $\begin{array}{l}\text { BW } \\
(\mathrm{MHz})\end{array}$ & VSWR \\
\hline 1.575 & 1.6 & 45.307 & 58.13 & 17.08 & -38.16 & 49 & 1.173 \\
\hline
\end{tabular}

\section{Conclusion}

In this paper firstly an inset fed microstrip antenna for GPS applications i.e. at the centre frequency of $1.575 \mathrm{GHz}$ has been designed with the help of transmission line theory. After calculating the various parameters such as width, effective dielectric constant, effective length and actual length, the antenna impedance is matched to $50 \mathrm{ohm}$. These results are obtained through MATLAB. And the result for the feed point thus obtained is used as the training data. After a large no. of training steps estimator's accuracy was found to be excellent. Optimized antenna are simulated by CST to verify the results obtained.

\section{References}

[1] G.A. Deschamps, 'Microstrip Microwave Antennas', Presented At the Third Usaf Symposium On Antennas, 1953.

[2] Constantine A. Balanis, 'Antenna Theory: Analysis Design', Third Edition, By ISBN 0-471-66782-X Copyright 2005 John Wiley \& Sons, Inc.

[3] R. Garg, P. Bhartia, I. J. Bahl, and A. Ittipiboon, Microstrip Antenna Design Handbook. Artech House(2001).

[4] Priti P. Bhagat, Dhaval Pujara and Dipak Adhyaru, 'Analysis and Synthesis of Microstrip Patch Antenna using Artificial Neural Networks', IEEE Asia-Pacific Conference on Antennas and Propagation, August 27-29, 2012, Singapore.

[5] Vipul Sharma, Member, IEEE, Gaurav Kumar Gupta, 'Using Artificial Neural Network to Model Microstrip Inset Fed Rectangular Patch Antenna', Dept. of Electronics \& Communication Engineering, Gurukul Kangri University, Haridwar-249404 (India).

[6] Osowski S., "Neural Networks", Polish Scientific Press, Warsaw, 1994. 